\title{
REPRESENTAÇÕES SOCIAIS DA EQUIPE DE ENFERMAGEM SOBRE A CRIANÇA DESNUTRIDA E SUA FAMÍLIA*
}

\author{
Maria Helena Ciampone** \\ Vera Lúcia Pamplona Tonete*** \\ Myriam Aparecida Mandetta Pettengill**** \\ Rosa Yuka Sato Chubaci*****
}

CIAMPONE, M.H.; TONETE, V.L.P.; PETTENGILL, M.A.M.; CHUBACI, R.Y.S. Representações sociais da equipe de enfermagem sobre a criança desnutrida e sua família. Rev.latino-am.enfermagem, Ribeirão Preto, v. 7, n. 3, p. 17-24, julho 1999.

O presente estudo derivou de nosso interesse em aprofundarmos nossos conhecimentos em relação à prática da enfermagem junto às crianças desnutridas e suas famílias. Nossos objetivos foram: compreender as representações sociais da equipe de enfermagem sobre a criança desnutrida e sua família e analisar como essas representações podem interferir no processo de cuidar. Baseando-nos nos princípios da pesquisa qualitativa, adotamos o referencial teórico-metodológico das representações sociais. Para coleta e análise dos dados utilizamos técnicas projetivas e análise de conteúdo do discurso, respectivamente. Os resultados apontaram para uma concepção ingênua dos profissionais de enfermagem, que reproduzem na prática assistencial um forte código moral e hábitos higiênicos à familia o que não propicia a formação de consciência crítica para lutarem por seus direitos de cidadania.

UNITERMOS: relações profissional-família,enfermagem em saúde comunitária, distúrbios da nutrição infantil

\section{INTRODUÇÃO}

O presente estudo derivou do interesse em aprofundarmos o conhecimento a respeito da prática da enfermagem com crianças desnutridas e suas famílias. Tal interesse emergiu de nossos encontros no Grupo de Estudos da Família na Escola de Enfermagem da Universidade de São Paulo-EEUSP, onde discutimos experiências vividas no atendimento de crianças desnutridas em nossos campos de ação profissional, quer seja no ensino, pesquisa e assistência.

Mesmo advindas de diferentes regiões do país e exercendo atividades distintas, pudemos perceber que havia muitas semelhanças na "forma" com que atuávamos junto às crianças desnutridas, principalmente no que se refere ao compartilhar da compreensão a respeito da necessidade de um maior envolvimento dos profissionais, com as famílias das crianças atendidas no processo terapêutico.
Podemos perceber que esse envolvimento da enfermagem com a família tem se dado de maneira empírica, isto é, baseado nas experiências pessoais de cada um, sem estar fundamentado em referencial teóricometodológico explícito. Ao passo que, a assistência prestada, embora se respaldando no conhecimento científico, tem sido pautada no modelo clínico essencialmente, voltada para o enfoque curativo, hospitalocêntrico e individual.

Assim, este estudo tem como preocupação romper com esta visão, voltando-se para um enfoque centrado na criança e sua família, partindo da visão mais ampliada de que a assistência de enfermagem não se restringe somente à patologia vista na perspectiva individual/biológica, devendo abarcar as dimensões biopsico-socio-espiritual.

Em função destas observações, surgiram algumas indagações que consideramos importantes, ou seja, como fazer com que os profissionais de saúde e particularmente

\footnotetext{
* Trabalho apresentado no IV Congresso Internacional de Enfermagem da Família, novembro 1997, Valdívia - Chile

** Enfermeira, Doutora em Psicologia Social, docente da Escola de Enfermagem da Universidade de São Paulo

*** Enfermeira, Doutoranda do Programa de Pós-Graduação da Escola de Enfermagem de Ribeirão Preto da Universidade de São Paulo, docente da FCM-UNESP-Botucatu

**** Enfermeira, Mestranda do Programa de Pós-Graduação da Escola de Enfermagem da Universidade de São Paulo, docente da Universidade Federal de Mato Grosso do Sul

***** Enfermeira, Mestranda do Programa de Pós-Graduação da Escola de Enfermagem da Universidade de São Paulo
} 
os da enfermagem compreendam a importância de assistir a família levando em consideração suas representações sobre o cuidar e o cuidado? Como trabalhar a necessidade de criar vínculos com a família para que a assistência seja mais efetiva? Como fazer com que percebam a necessidade de rever os paradigmas do grupo técnico considerados unilateralmente como verdadeiros?

Desta forma, adotamos como objeto deste estudo, especificamente, as representações da equipe de enfermagem em relação à criança desnutrida e a sua família, em cenários de contrastes sócio-econômicos, no intuito de possibilitar o esclarecimento das questões acima enunciadas e caminhar no sentido de constituir propostas de intervenção mais integradas com a realidade e quiçá contribuir na construção do conhecimento que resulte em condutas e comunicações mais humanizadas.

A problemática da desnutrição infantil vem sendo objeto de vários estudos dada à importância e magnitude que assume nos países periféricos. Constatamos que, em grande parte das pesquisas, o enfoque concentra-se nos fatores condicionantes explorando os aspectos biológicos conseqüentes à ocorrência da desnutrição. Nos últimos anos, observamos uma tendência analítica que permite que se possa explicitar, também, questões psicossociais envolvidas no problema e, conseqüentemente, a busca de solução. Como exemplo dessa análise diferenciada encontramos CARRAZA (1992) que define má nutrição ou desnutrição energético-proteica (DEP) como "uma gama de condições patológicas com deficiência simultânea de proteínas e calorias, em variadas proporções que acomete, preferencialmente, crianças de baixa idade e comumente associadas com infecções". Para esse autor os fatores etiológicos mais importantes são o "baixo nível sócio-econômico (pobreza - privação nutricional) e seus acompanhantes intrínsecos: as más condições ambientais (infecção - hospitalização), o baixo nível educacional e cultural (criança negligenciada - falta de amamentação - privação afetiva)".

NÓBREGA \& CAMPOS (1994) afirmam que muitos são os fatores relacionados à desnutrição, não descartando as condições sócio-econômico-culturais, porém associando a estes determinantes características da personalidade materna que levam a frágil relação vincular mãe-bebê ou inexistente. Para esses autores as questões referentes ao vínculo mãe-filho estão sempre presentes na base das demais dificuldades.

MONTEIRO et al. (1995), comparando dois inquéritos nacionais realizados no Brasil em 1975 e 1989, indicam um balanço favorável do ponto de vista nutricional, com redução em mais de $60 \%$ na prevalência da desnutrição. Para esses autores as evidências recolhidas, em relação à situação econômica, indicam ganhos substanciais na década de 70 e apenas parciais na década de 80 . Quanto à correlação entre a cobertura de serviços de saneamento, saúde e educação e a oferta de programas de suplementação alimentar, os autores citados consideram que a evolução foi excepcionalmente favorável ao longo das duas décadas. Porém enfatizam que, apesar da redução dos casos, devemos ser muito cautelosos, pois essa "melhoria" teve sua concentração na década de 70 , pouco se elevando na década de 80 , ressaltando que também não tem havido sinais de recuperação da atividade econômica, aliada à ameaça de cortes sobre os gastos sociais do governo, agravando-se a injusta distribuição da renda nacional, concluindo que será improvável que se repitam estes avanços observados nos próximos anos.

De acordo com LEÃO \& FIGUEIREDO FILHO (1989) as formas leves e moderadas da desnutrição nem sempre são diagnosticadas, não recebendo tratamento adequado.

Assim, acreditamos ser este um grave problema de Saúde Pública e que nós, enfermeiras, enquanto membros da equipe de saúde, devemos refletir e nos posicionar buscando formas de intervenção que contribuam na sua resolutividade. Uma dessas formas, em nossa opinião, que tem um significado primordial e que não observamos ser muito enfatizado é o desenvolvimento de estratégias de assistência envolvendo a família. Acreditamos que a família exerce grande poder de influência em relação à saúde de seus membros, sendo que o sucesso de um trabalho terapêutico depende, principalmente, da sua participação para concretizar-se, muito embora não seja do domínio da mesma controlar as causas determinantes do contexto econômico-social.

Quando falamos em família, percebemos a intimidade desta palavra. Por ser comum a cada um de nós, parece ser fácil conceituarmos, pois, geralmente, trazemos como referência internalizada a nossa própria família. Porém, após alguns instantes de reflexão sobre o assunto não nos parece ser tão fácil assim, pois cada um tem a sua definição, conforme a sua visão contextual e experiência.

Segundo CARTER \& MC GOLDRICK (1989), a definição de família varia de acordo com o "background" cultural de cada um, o qual compreende todo o sistema emocional de pelo menos três a quatro gerações. Enfatizam as diferenças sociais e étnicas das pessoas e que, além da família nuclear composta por pai, mãe e filhos, existem outras conformações familiares, dadas por relações íntimas com outras gerações (família ampliada).

Observando estas definições, podemos considerar que o conceito de família vem se modificando e ampliando através dos tempos e que a família tradicional burguesa, ou seja, a nuclear, vem tendendo a diminuir. Verificamos que, freqüentemente, fazem parte da família todos aqueles que constituem vínculos significativos, sem 
dar importância a fatores como a consangüinidade. Assim, compartilhamos com Manciaux apud ELSEN (1994), quando afirma que a "família não se define, ela se mostra por si".

Conforme MAURER \& BELLACK (1984) a criança e a família possuem interações físicas, emocionais, psíquicas e sociais um com o outro. É neste ambiente que a criança interage quase que, exclusivamente, nos primeiros anos de sua vida, adquirindo sua identidade, sua posição individual na rede de interações sociais. Portanto, o bebê ao nascer já pertence a uma rede familiar, continuando a estabelecer vínculos que se iniciaram a partir do ventre da mãe.

É sabido que a criança, sendo um ser em crescimento e desenvolvimento, necessita de um ambiente de acolhimento e afeto para que suas necessidades básicas de cuidado, alimentação, aprendizagem e carinho sejam atendidas. É sabido também, que ambientes conflitantes e instáveis podem prejudicar a saúde da criança.

CARTER \& MC GOLDRICK (1989) afirmam que o vínculo que se estabelece no decorrer do ciclo de vida entre os membros da família faz com que um simples "stress" de um de seus membros cause uma interrupção no ciclo de vida normal da mesma. Tal interrupção pode ser causada, também, por problemas biológicos, sociais e emocionais, podendo levar a família, ou algum de seus membros a um estado de doença.

Segundo ELSEN (1994), quando a agressividade torna-se freqüente dentro da família, pode trazer conseqüências negativas para a saúde de seus membros, afetando-os em sua integridade física ou emocional. Por outro lado, em uma família saudável, onde existe a ajuda mútua, há uma melhor adaptação dos seus membros frente a um problema, colaborando e ajudando a pessoa doente na sua recuperação.

$\mathrm{Na}$ situação atual em que vivemos, o ciclo de vida normal de uma família pode sofrer desvios em razão de muitos fatores. O desemprego, a miséria, falta de moradia, educação inacessível, desinformação, afastamento da mãe por longo tempo de seu filho, entre outros constituem fatores que podem levar a um "desvio da saúde familiar".

Um destes fatores, pesquisados por GOLDENBERG (1989), diz respeito à desnutrição infantil, em que a autora motivada pela alta taxa de mortalidade infantil na década de 60 , fez um estudo para apreender a desnutrição como causa da mortalidade infantil em menores de 1 ano de idade. Neste estudo observou-se a diferença significante quanto ao estado nutricional das crianças nas famílias nucleares $(27 \%$ de desnutridos) e ampliadas (19,2\% de desnutridos). Observou-se que as famílias ampliadas possuíam maior renda per capita que as nucleares. Porém, podemos supor que, além da situação econômica, a família ampliada possui, também, uma rede de interações ampliadas, onde a criança tem com quem ficar e por quem ser cuidada.

Segundo OLIVEIRA (1994), como cuidadores devemos saber ouvir, compreender e respeitar a família. Apreender os significados dos problemas e suas conseqüências para ela. O profissional deve tentar compreender os fatores que alteram o cotidiano familiar para que possa ajudá-los na adaptação ativa a este contexto e reforçar a importância desta em participar do tratamento da criança.

NÓBREGA \& CAMPOS (1996) afirmam que os pais, especialmente a mãe, são pessoas caluniadas, sobretudo pelos profissionais, tanto médicos como de outras áreas afins. Para os autores os problemas surgem porque os próprios pais têm dificuldades emocionais, pois, quando crianças sofreram privações afetivas, tornando-se adultos incapazes da continência dos problemas de seus filhos. Conclui que não é possível dar o que não se recebeu.

Assim, buscando elucidar nosso objeto, estabelecemos como objetivos deste estudo: compreender as representações sociais dos profissionais da equipe de enfermagem sobre a criança desnutrida e sua família, em cenários de contrastes sócio-econômicos; e analisar como as representações desses profissionais podem interferir no processo de cuidar.

Como não advogamos a favor da neutralidade do pesquisador diante do objeto em estudo, passamos a explicitar alguns pressupostos que temos a respeito das possíveis representações dos profissionais de enfermagem à respeito da temática: existem preconceitos na forma com que os profissionais da equipe de enfermagem vêem a criança desnutrida; as famílias são responsabilizadas, diretamente, pela situação nutricional de seus membros; as famílias são acusadas de negligentes e despreparadas para o cuidado com a criança desnutrida e devem ser orientadas para o cuidado; os profissionais atribuem a falta de alimento como causa única da desnutrição e, apenas, a recuperação do peso como sinal de melhora; a família é vista como a causa do problema e parte fundamental na sua resolução.

\section{O REFERENCIAL TEÓRICO- METODOLÓGICO DO ESTUDO}

Seguindo a abordagem de pesquisa qualitativa, fundamentamo-nos no referencial teórico das representações sociais por admitir que tal opção possibilita-nos a aproximação pretendida neste estudo, ou seja, compreender os significados que a equipe de enfermagem atribui à desnutrição infantil, permitindonos, desta forma, olhar sob outra perspectiva as relações 
que se estabelecem entre estes profissionais, as crianças desnutridas e suas famílias.

Entendemos que as representações sociais dizem respeito ao pensamento do senso comum, que por sua vez permeiam as relações humanas nas diferentes instâncias sociais, acreditando ser a compreensão do senso comum uma condição muito importante senão essencial para a compreensão da realidade social, quando se considera que os sujeitos dessas relações são agentes ativos no processo de criação e recriação da mesma.

Deste modo, tomamos como conceito de representações sociais a de Jordelet apud SÁ (1993) que as considera como "uma forma de conhecimento, socialmente elaborada e partilhada, tendo uma visão prática e concorrendo para a construção de uma realidade comum e um conjunto social". Sendo que a apreensão das representações sociais, segundo GOULART (1993), dá-se "através de estudos específicos, levando em conta um contexto sempre em mudança, marcado pelo caráter contraditório das relações sociais, dentro do qual a representação não deve ser buscada como única explicação do fenômeno, mas sim como fator facilitador da comunicação". Porém, cabe-nos apontar também, o caráter da transdisciplinaridade intrínseca ao campo de estudo das representações sociais, salientado por SPINK (1993), o que permite constituir-se como "elemento central em vários campos do saber".

Para SPINK (1989), o processo saúde/doença constitui um campo fértil para os estudos de representação social, porque embora o modelo médico tenha reduzido a saúde/doença ao estado orgânico do corpo individual ou coletivo, definido e cuidado pelas instituições de saúde (nas quais historicamente a enfermagem se insere), a doença extrapola os limites da individualidade e do diagnóstico estritamente clínico. Buscar seu significado remete, necessariamente, a uma interpretação coletiva complexa, em constante movimento, o que por sua vez remete ao discurso da sociedade sobre as enfermidades e os enfermos. Ainda, segundo essa autora, as representações sobre saúde/doença permitem evidenciar as complexas relações entre o biológico e o social, explorar a interface entre senso comum e o pensamento científico, possibilitando explicitar o tipo de relações sociais que se estabelecem na prática cotidiana.

Partilhamos da perspectiva compreensiva do fenômeno desnutrição/nutrição como um fenômeno que se manifesta no corpo individual dos sujeitos, mas que tem por causas, forças que emanam do social que determinam as condições de vida e, em última instância, o modo de adoecer e morrer da coletividade. Isto implica em afirmar que as sociedades agem sobre os seus indivíduos independentemente da vontade destes, conformando diferentes perfis de morbi-mortalidade a grupos distintos.
O CAMPO E A TÉCNICA DE ANÁLISE DOS DADOS

O campo onde se buscou mapear as representações da equipe de enfermagem em relação à criança desnutrida e sua família, constituiu-se em uma unidade básica de saúde, localizada na cidade de Botucatu, Estado de São Paulo.

Através do contato mantido por uma das pesquisadoras no campo, divulgamos o interesse na realização da pesquisa, bem como os objetivos pretendidos e solicitamos colaboração dos sujeitos para participar, tendo obtido o consentimento informado de 10 sujeitos, sendo 3 Técnicos de Enfermagem, 4 Auxiliares de Enfermagem e 3 Atendentes de Enfermagem, para gravarmos as entrevistas que foram previamente agendadas com todos que se dispuseram a falar sobre o tema. As entrevistas foram realizadas durante o mês de março e abril de 1997, sendo posteriormente transcritas na íntegra, compondo-se no material por nós analisado.

Primeiramente, foi mostrado aos sujeitos uma seqüência de figuras, solicitando-se a eles que, por meio de associação livre, discorressem sobre as mesmas respondendo às questões que lhes eram formuladas na seqüência: o que representa para você esta figura? (figura onde evidenciam-se diferentes tipos de alimento); que fatores você considera que interferem no consumo de alimentos? Em seguida, trocava-se por outra seqüência de figuras, perguntando-se: quem são essas pessoas e como elas vivem? Quais são os principais problemas que elas enfrentam? (figuras representando famílias extremamente pobres). Na seqüência, contrapunha-se com outras figuras representando famílias de classe média e repetia-se as mesmas questões formuladas, anteriormente.

Posteriormente, apresentou-se a eles figuras de crianças desnutridas e bem nutridas, perguntando-lhes: Quem são essas crianças? Quais as causas que as levaram a ficar como estão? Que ações precisariam ser tomadas para a assistência à saúde delas?

Para tanto, baseamo-nos em SÁ (1996), que propõe para a coleta de dados, o uso de figuras ou desenhos como técnicas projetivas, que possibilitam a captação dos "mapas associativos" dos sujeitos, sendo que neste estudo, esta captação foi realizada através da perspectiva qualitativa, não sendo empregada a análise de freqüências, nem tampouco outra técnica quantitativa.

Sobre o material discursivo, então, são realizadas várias leituras, ditas flutuantes, no sentido de obter familiaridade com o conteúdo, de modo a captar as principais unidades de significação nele contidas, que, em uma segunda etapa, esse material é submetido à 
análise de similitudes ou divergências em torno dos eixos ou fatores gerais que organizam a representação.

Dando continuidade, extrai-se os elementos que compõem o núcleo central das representações que constituem-se nos supostos elementos que se conectam com um maior número de unidades associativas, que, por esse motivo, são designadas de núcleos centrais e os demais núcleos periféricos.

Assim, busca-se colocar em evidência esses elementos estruturantes e centrais da representação que permitem entendermos como se dá a conexidade associativa entre os diferentes núcleos figurativos. $\mathrm{O}$ caráter espontâneo, portanto menos controlado, e a dimensão projetiva dessa produção permitem o acesso menos "contaminado" às representações do que na entrevista convencional.

Esta técnica busca criar um conjunto de categorias, que organizam as representações. O tratamento dos dados, em termos de análise de similitude, leva-nos a um tipo de estruturação das falas definidas como "estrela", isto é, os núcleos centrais da representação configuram-se dando uma noção que alguns elementos originam e ligam-se a muitos outros, assumindo a forma de uma estrela.

Salientamos que as figuras utilizadas apresentavam cenas extremas de pobreza x riqueza; de crianças gravemente desnutridas $\mathrm{x}$ visivelmente bem nutridas; de ambientes insalubres $\mathrm{x}$ locais agradáveis e salubres. Deste modo, buscamos correlacionar os contrastes da realidade atual com o tema de nosso estudo. Embora tenhamos enfocado apenas a análise do material referente à questão das famílias de crianças desnutridas, usamos como indução um cenário ambíguo, que sugeria contrastes. Não sendo nossa preocupação a neutralidade no processo de seleção e aplicação das figuras, mas sim, assumir a concepção da determinação social do processo saúde/doença, a qual afirma que existe uma correlação direta entre as condições de vida e o risco de adoecer/ morrer.

Compartilhamos com Breilh apud EGRY ${ }^{3}$ que concebe o processo saúde/doença como a "síntese do conjunto de determinações que operam numa sociedade concreta, produzindo nos diferentes grupos sociais o aparecimento de riscos ou potencialidades característicos, por sua vez manifestos na forma de perfis ou padrões de doença ou saúde. Certamente, a qualidade de vida a qual cada grupo sócio-econômico está exposto é diferente e, portanto, é igualmente diferente sua exposição a processos de risco que produzem o aparecimento de doenças e formas de morte específicas, assim como, seu acesso a processos benéficos ou potencializadores da saúde e da vida".

É válido ressaltar que a utilização destas figuras que mostram cenários contrastantes poderia reforçar os

esteriótipos "desnutrição/pobreza" e "nutrição/melhores condições sócio-econômicas", porém, conforme as considerações expostas anteriormente, são os perfis mais expressivos de saúde e doença relativos a estes grupos, mesmo levando em conta as variações possíveis destes padrões, tais como, encontrar crianças com má nutrição em grupos sócio-econômicos mais favorecidos (geralmente por erros alimentares ou outros problemas) e por outro lado, crianças bem nutridas em grupos sócioeconômicos menos favorecidos, o que julgamos ser exceções, conforme podemos verificar na análise apresentada a seguir.

\section{APRESENTAÇÃO E ANÁLISE DOS RESULTADOS}

O material aqui apresentado, constituiu-se da síntese extraída dos conteúdos dos discursos dos dez sujeitos participantes do estudo. O tempo de cada entrevista variou de 25 a 65 minutos, tendo o conteúdo sofrido primeiramente uma análise individual e tendo sido posteriormente agrupado, de acordo com os critérios já citados, anteriormente.

Os núcleos centrais extraídos das representações geradas a partir das figuras que sugeriam oferta diversificada de alimentos e acesso a eles foram:

TR A B ALHO/
EMPREGO
Dinheiro
Alimentos
Vida Saudável
Fartura
Acesso à bens
Poucos são ricos
Com poder
Regem o país

As associações acima estabelecidas através do contraste das imagens, remetem a dois núcleos centrais que são trabalho/emprego e não trabalho/desemprego, demonstrando entre os sujeitos forte saliência quantitativa compondo, assim, diversas associações com outros núcleos figurativos a eles conectados.

Os qualificativos atribuídos às pessoas pertencentes as categorias de trabalhadores/empregados e de não trabalhadores/desempregados foram respectivamente pessoas que: vivem bem; têm poder aquisitivo; são felizes; podem se reunir; podem se distrair; têm fartura; estão contentes; estão alegres; podem passear; têm lazer; moram confortavelmente; dignamente, com higiene, com esgoto, água e luz; não têm problemas a 
não ser de doenças não evitáveis; têm privilégios, têm vida saudável. Apareceram, também, citações atribuídas a estas pessoas correlacionando a má nutrição (hipovitaminoses, anemia, hipertensão e obesidade) com o desconhecimento das mesmas sobre como ter uma alimentação adequada. Porém, confirmando o exposto, estas situações foram pontuadas como menos freqüentes: estão se alimentando, não estão se nutrindo; pode ter anemia por não saber alimentar-se direito; comem e bebem muito, podem ficar obesos; gordura, colesterol, pressão alta.

Quanto à segunda categoria as associações foram: coitados; pobrezinhos; vivem no lixão; amontoados em favelas; convivem com ratos; vivem pessimamente; sobrevivem à miséria; as crianças trabalham; não tem esgoto, não tem água encanada; estão desabrigados; prostituição; álcool; drogas; não estudam; abandonam suas famílias; sentem-se rejeitados; não encontram ajuda; vivem de esmolas; roubam; cometem crimes; vivem nas ruas; são desnutridos, desidratados, passam fome; tem um monte de doenças e carências; se sentem humilhados; metem medo na gente. As associações desta categoria com aspectos positivos de saúde, como pressupúnhamos, não foram evidenciadas, a não ser as citações que destacam a possibilidade de serem saudáveis e bem nutridas se lhes forem oferecidos: o básico de alimentos; oportunidades de emprego; orientações sobre saúde e cuidados com as crianças.

As associações em torno do núcleo central trabalho e não trabalho configuram uma representação social pautada na concepção de que a inserção do indivíduo no mundo do trabalho é que vai possibilitar a ele condições de vida e de reprodução social satisfatória.

$\hat{E}$ interessante salientar que não foram evidenciadas associações do núcleo central trabalho, com as atividades socialmente valorizadas e que implicam em remuneração adequada e justa que permitem que o sujeito/ família tenham acesso à uma vida digna e com todos os atributos positivos a ele associados. Sabemos bem, que em nosso país além do crescimento da taxa de desemprego, evidencia-se uma vinculação crescente do trabalhador com o mercado informal, sem nenhuma garantia ou seguridade social.

$\mathrm{Na}$ perspectiva de uma sociedade inserida na globalização, professa-se a crença na força reguladora do mercado, demarcando caminhos díspares, uma espécie de encruzilhada cruel que marca, no país, o último embate do pensamento político e social no final deste século, antecipando que no início do século XXI teremos um panorama de "prosperidade geral" assentado sobre uma situação de "miséria renitente".

Assim, as associações simples de garantia das condições de vida das famílias mediadas pelo trabalho, não estando este caracterizado, constitui-se em uma concepção ingênua da realidade.

A constatação de que finalizamos o século XX, sem atingirmos a meta projetada "saúde para todos no ano 2000 ", nos permite inferir que existe ainda muito trabalho escravo, de adultos e crianças.

Sobre a educação como base para um trabalho melhor, o diagnóstico seria de que o próximo século está tremendamente ameaçado, dada a qualidade do ensino e as possibilidades reais de acesso a ele. Sem fortalecimento da educação, inviabiliza-se a desejada expansão tecnológica.

$\mathrm{Na}$ concepção ingênua dos sujeitos o simples trabalho redunda na possibilidade da família sair de uma posição marginal. É interessante destacar, que embora não tenham sido associações dominantes, apreende-se que existem representações que passam pelo julgamento de que muitos não têm trabalho porque se acomodam à vida de pedinte e se tornam vagabundos e preguiçosos. Encontramos, ainda, certa tendência na culpabilização da mãe que não quer amamentar seu filho; que não sabe administrar o pouco que tem, gastando em besteiras ou dando alimentação inadequada. Ressaltou-se ainda que só passa fome quem é preguiçoso e não planta uma hortinha no fundo do quintal.

Tais representações encontram-se fortemente estruturadas na ética dominante do liberalismo, que apregoa a "ordem para o progresso" e a livre competição no mercado que privilegia os melhores. Contudo os sujeitos/trabalhadores da enfermagem que mantém tais representações submetem-se ingenuamente à premissa contida nesta assertiva, que todos competem no mercado em igualdade de condições, o que é absolutamente não verdadeiro.

Desse modo compreendemos que as representações sociais são perpetuadas e estruturam formas de pensar e agir, que delineiam o senso comum sobre as raízes da pobreza e da miséria que se assenta em causas individuais. $\mathrm{O}$ pensamento, assim fragmentado e desarticulado da totalidade, tem gerado ações "corretivas" que não incidem sobre as causas reais dos problemas, resumindo-se aos sintomas.

Isso se confirma nas propostas de ação delineadas pelos sujeitos do estudo, para intervir sobre a problemática da desnutrição, que restringem-se à inserção das crianças no programa de leite e em orientações sobre as necessidades de higiene e alimentação balanceada.

A visita domiciliar é percebida como incentivo aos pais, como apoio a eles diante da situação familiar vivida. Mais uma vez a associação de que "não arruma 
emprego, porque não tem animo de arrumar". A orientação implica também, segundo as representações, "na palavra amiga e solidária do profissional de enfermagem", fortemente arraigada na concepção humanista/assistencialista.

O "dar o sorinho", também foi fortemente evidenciado como ação de enfermagem, visando hidratar a criança. Ensinar a fazer o soro caseiro, melhorar o programa de orientação, desde o nascimento do bebê, ajudaria a prevenir a desidratação e a desnutrição.

A ajuda, no sentido de estabelecimento de uma política que favoreça o emprego, "mesmo que ganhe salário mínimo", também foi contemplada na representação dos sujeitos como ação efetiva.

Outra associação, que também denota cunho assistencialista, foi evidenciada pela necessidade do profissional promover campanhas para arrecadar alimentos na comunidade. Contudo, a ação solidária, embora constitua-se em possibilidade de ajuda, não evidencia um rompimento com o pensamento ingênuo na direção de uma reflexão mais crítica da situação.

Desse modo, a orientação sobre o certo, não agrega elementos à formação da cidadania, da busca pelos direitos, aos quais a Constituição refere-se. Ao contrário as informações de cunho higienista e moralista são pouco objetivas e resolutivas.

Para finalizar, tomamos como porta-voz da desassistência a fala de um dos sujeitos do estudo, referindo-se à falta de orientação da clientela assistida, citando como exemplo uma mãe que julga revoltada: " $\boldsymbol{E} \boldsymbol{u}$ uso droga, porque quando eu tô drogada eu acho que a vida tá bela, tudo tá bonito pra mim, eu esqueço o sofrimento, eu esqueço, então tá tudo bom pra mim..." Quando indagada pela profissional se não tem medo do futuro, responde: “Ah! Eu não penso no futuro...eu penso no agora."

Embora os sujeitos tenham em alguns momentos demonstrado tristeza, indignação e até revolta diante da desigualdade, o pensamento e a ação se mostram imobilizados para encontrar saídas que rompam com a postura desarticulada e pacífica a que tem sido submetidos os "dóceis corpos do hospital", que também se mostram "dóceis" em outros espaços da assistência e da vida.

\section{CONCLUSÃO}

Diante dos núcleos centrais sobre os quais se constrói a representação social da equipe de enfermagem acerca da criança desnutrida e sua família, destacamos alguns aspectos, que confirmam os pressupostos por nós formulados no início deste estudo, ou seja: a enfermagem, ainda hoje, reproduz na prática assistêncial um forte código moral e hábitos higiênicos, que evidenciam uma concepção de processo saúde-doença pautada na multicausalidade ou na unicausalidade; a relação vincular no âmbito familiar é abordada por alguns dos sujeitos, porém, não se destacando como aspecto relevante. A representação aí contida é de que algumas mães não estabelecem vínculo para cuidar dos filhos, sendo que estas mães são aquelas desempregadas, alcoolizadas e que muitas vezes abandonam as crianças. A resolutividade da desnutrição limita-se, contudo, à possibilidade de melhoria do peso da criança, com o consumo alimentar adequado; o cotidiano profissional nos mostra que embora o discurso se paute na assistência à família, a prática evidencia-se como humanista, porém, impregnada por concepções ingênuas e limitadas da realidade social, dentro da qual se insere, de uma forma dialética a problemática da família sobre a qual pretendese atuar. A formação profissional precisa ser reformulada de modo a reforçar conteúdos que favoreçam a formação de atitudes ético-políticas, que permitam um repensar mais crítico acerca da realidade no sentido da transformação dessas representações sociais cristalizadas, das quais os sujeitos deste estudo são os porta-vozes; a relação dominação-subordinação, reiterada na postura dos profissionais de enfermagem, não propicia o desenvolvimento da consciência crítica das famílias de modo a lutarem por seus direitos de cidadania na defesa da almejada eqüidade social.

\section{SOCIAL REPRESENTATIONS OF A NURSING TEAM ABOUT UNDERNOURISHED CHILDREN AND THEIR FAMILIES}

The present study derived from our interest in nursing practice with the undernourished children and their families. Our objectives were: to understand the social representations of the nursing team about undernourished children and their families and to analyze how these representations can interfere in the process of taking care. Based on qualitative research principles, authors adopted the social representations theoretical method. For data collection and analysis, authors used the projective techniques and speech subject analysis, respectively. Results showed an innocent conception by nursing professionals, that reproduces in the practical field a strong moral code and hygienic habits to the family and it does not propitiate the formation of a critical conscience about their citizenship rights. 


\title{
REPRESENTACIONES SOCIALES DEL EQUIPO DE ENFERMEROS SOBRE EL NIÑO DESNUTRIDO Y SU FAMILIA
}

\begin{abstract}
El presente estudio se derivó de nuestro interés con respecto a la práctica de enfermería con niños desnutridos y sus familias. Nuestros objetivos fueron: comprender las representaciones sociales de los profesionales del equipo de enfermería que trabajan directamente con familias de niños desnutridos a respecto del proceso de desnutrición y analizar cómo las representaciones de esos profesionales pueden interferir en el proceso de cuidar. Con base en los principios de la investigación cualitativa adoptamos por el referencial teórico metodológico de las representaciones sociales. Para la obtención y análisis de los datos utilizamos técnicas proyectivas y análisis de contenido del discurso, respectivamente. Los resultados mostraron una concepción ingenua del trabajo de enfermería, que reproducen en la práctica asistencial un fuerte código moral y hábitos higiénicos a la familia lo que no facilita la formación de una consciencia crítica para luchar por sus derechos de ciudadanía.
\end{abstract}

TÉRMINOS CLAVES: práctica de enfermería familiar, enfermería en la salud comunitaria, niño desnutrido

\section{REFERÊNCIAS BIBLIOGRÁFICAS}

01. CARRAZA, F.R. Distúrbios nutricionais crônicosdesnutrição. In: MARCONDES, E. Pediatria básica. São Paulo: Sarvier, 1992. v. 1, p. 635643.

02. CARTER, B.; MC GOLDRICK, M. As mudanças no ciclo de vida familiar. Trad. por Maria Adriana Veríssimo Veronese. Porto Alegre: Artes médicas, 1989. 510p. Tradução de The change family life cycle: a framework for family therapy.

03. EGRY, E.Y. A saúde coletiva: construindo um novo método em enfermagem. São Paulo: Icone, 1996. $144 \mathrm{p}$.

04. ELSEN, I. et al. Marcos para a prática de enfermagem com famílias. Florianópolis: UFSC, 1994. 195p.

05. GOLDENBERG, P. Repensando a desnutrição como questão social. 2.ed. São Paulo: Cortez, 1989. $159 \mathrm{p}$.

06. GOULART, F.A.A. Representações sociais, ação política e cidadania. Cad. Saúde Pública, Rio de Janeiro, v. 9, n. 4, p. 477-486, 1993.

07. LEÃO, E.; FIGUEIREDO FILHO, P.P. Desnutrição. In: LEÃO, E. et al. Pediatria ambulatorial. Belo Horizonte: Coopmed, 1989. p. 156-161.

08. MAURER, J.; BELLACK, J.P. Family assesment. In: BELLACK, J.; BANFORD, P. Nursing assessment: a multidimencional approach. Monterey: Wadsworth, 1984. Cap.11, p. 205-225.
09. MONTEIRO, C.A. et al. Velhos e novos males da saúde no Brasil: a evolução do país e de suas doenças. São Paulo: HUCITEC-NUPENS/USP, 1995.

10. NOBREGA, F.J.; CAMPOS, A.L.R. Distúrbios nutricionais e fraco vínculo mãe/filho. Rio de Janeiro: Revinter, 1994.

11. OLIVEIRA, A.G.C.de. Convivendo com a doença crônica da criança: a experiência da família. São Paulo, 1994. Tese (Doutorado) - Escola de Enfermagem, Universidade de São Paulo.

12. SÁ, C.P. Representações sociais: o conceito e o estado atual da teoria. In: SPINK, M. J. P.(org). O conhecimento do cotidiano: as representações sociais na perspectiva da psicologia social. São Paulo: Brasiliense, 1993. p.19-45

13. Núcleo central das representações sociais. Petrópolis: Vozes, 1996.

14. SPINK, M.J.P. As representações sociais e sua aplicação em pesquisa na área da saúde. In: CONGRESSO BRASILEIRO DE SAÚDE COLETIVA, 2 e CONGRESSO DE SAÚDE PÚBLICA, 3. São Paulo, 1989. (mimeografado).

15. .O conceito de representação social na abordagem psicossocial. Cad. Saúde Pública, Rio de Janeiro, v. 9, n. 3, p. 300-308, 1993. 